\title{
INFLUÊNCIA DA UTILIZAÇÃO DE COBERTURAS VEGETAIS NA ESTRUTURA FÍSICA DO SOLO
}

Fernando Takayuki Nakayama ${ }^{1}$

Enes Furlani Junior ${ }^{2}$

Samuel Ferrari

Maurício Nasser

RESUMO: Os objetivos de uma agricultura sustentável são o desenvolvimento de sistemas agrícolas que sejam produtivos, conservem os recursos naturais, protejam o ambiente e melhorem as condições de saúde e segurança a longo prazo. Neste sentido, as práticas culturais e de manejo, como a rotação de culturas, o plantio direto, e o manejo do solo conservacionista, são muito aceitáveis, pois além de controlarem a erosão do solo e as perdas de nutrientes, mantêm e/ou melhoram a produtividade do solo. O trabalho foi desenvolvido na FAP/UNESP, Campus de Ilha Solteira - SP, localizada em Selvíria-MS, ( $20^{\circ} 22^{\prime} \mathrm{S}, 51^{\circ} 22^{\prime} \mathrm{W}$ ) com altitude média de 335 metros enquadrada na região de Cerrado. O objetivo do trabalho foi avaliar a influência da utilização de coberturas vegetais na estrutura física do solo em sistema de plantio direto. Os atributos físicos do solo de umidade gravimétrica e resistência à penetração são modificados após 3 anos de cultivo de plantas de cobertura. A camada superficial do solo correspondente à profunidade de $0-15 \mathrm{~cm}$ é interferida pelo cultivos de

\footnotetext{
${ }^{1}$ Eng. Agr., Pesq. Científico/APTA. fnakayama@apta.sp.gov.br

${ }^{2}$ Eng.Agr. Docente/Feis-Unesp. E-mail.
} 
plantas monocotiledôneas e as camadas mais profundas, de $30-45 \mathrm{~cm}$ são alteradas por plantas dicotiledôneas quanto à resistência à penetração.

Palavras-chave: manejo conservacionista, coberturas vegetais, física do solo.

\section{INTRODUÇÃO}

A agricultura sustentável objetiva o desenvolvimento de sistemas agrícolas que sejam produtivos, conservem os recursos naturais, protejam o ambiente e melhorem as condições de saúde e segurança a longo prazo. Neste sentido, as práticas culturais e de manejo, como a rotação de culturas, o plantio direto, e o manejo do solo conservacionista, são muito aceitáveis, pois além de controlarem a erosão do solo e as perdas de nutrientes, mantêm e/ou melhoram a produtividade dos solos. Alguns autores como Alcântara \& Bufarah (1986) enfatizam que um bom preparo do solo é fundamental para a germinação e desenvolvimento homogêneo da cultura e sugerem a adoção de sistemas de preparo do solo que reduzam as perdas de terra e proporcionem maior aproveitamento da água.

Uma das características do solo que mais sofre influência do manejo é a estrutura que pode ser considerada o componente básico de sua física, ao condicionar o desenvolvimento da porosidade intra e interagregados, como a principal via de circulação da água e do ar no solo. A estrutura que envolve uma série de inter-relações muito sutis, estabelecidas entre os componentes minerais e orgânicos do solo e que resulta de uma série de processos físicos, químicos e biológicos, pode facilmente se deteriorar pela ação das forças de compressão derivadas do uso incorreto de máquinas e implementos agrícolas. Os restos vegetais deixados na superfície do solo em manejos conservacionistas repercutem muito no aumento e na conservação da estabilidade de agregados na superfície e na redução da compactação das camadas subsuperficiais. Uma característica essencial de um solo produtivo é que ele seja capaz de manter uma dotação adequada de ar e água as raízes vegetais. A ênfase dada à estrutura do solo como fator de produção agrícola deve-se, em grande parte, ao fato de produção agrícola deve-se, em grande parte, ao fato de serem o ar e a água os ocupantes 
básicos dos espaços vazios (OTONNI FILHO, 2003). A compactação do solo constitui um tema de crescente importância em face do aumento da mecanização nas atividades agrícolas, que acarreta alteração no arranjo das partículas do solo, tornando mais denso. Os principais efeitos negativos da compactação do solo são o aumento da resistência mecânica ao crescimento radicular, redução da aeração e da disponibilidade de água e nutrientes, e, conseqüentemente, decréscimo na produtividade agrícola (WENCESLAU et al, 2002). A qualidade física de solos agrícolas pode ser afetada pelo sistema de manejo, sendo a magnitude das alterações dependente do tempo de uso do solo e das condições edafoclimáticas.(Costa et al, 2003)

Parte da água retida no solo é perdida por evaporação e/ou evapotranspiração e, em função da capacidade de infiltração e retenção de água do solo e da intensidade das chuvas, parte pode exceder e ser perdida por escoamento superficial. Dependendo do volume e da velocidade deste escoamento, pode ocorrer o arraste de partículas de solo e dos insumos nele aplicados, sedimentando-se em baixadas, lagos e rios, o que afeta gradativamente a capacidade produtiva do solo, reduzindo entre outros fatores, a sua fertilidade, a capacidade de infiltração e a retenção de água. Assim, pode-se dizer que a proteção da superfície do solo nos sistemas de manejo evita perdas de umidade por evaporação, O objetivo deste projeto é avaliar a influência da utilização de coberturas vegetais na estrutura física do solo em sistema de plantio direto

\section{MATERIAIS E MÉTODOS}

O trabalho foi desenvolvido na Fazenda Experimental da Faculdade de Engenharia UNESP, Campus de Ilha Solteira - SP, localizada em Selvíria no sudeste de Mato Grosso do Sul ( $20^{\circ} 22^{\prime} \mathrm{S}, 51^{\circ} 22^{\prime} \mathrm{W}$ ) com altitude média de 335 metros enquadrada na região de Cerrado. A quantidade e a freqüência de chuvas que ocorrerem no experimento, bem como as médias de temperatura e umidade relativa do ar, foram obtidas no Posto Meteorológico da Fazenda Experimental da FEIS-UNESP. O clima da região, segundo a classificação de Köppen, é do tipo Aw, definido como tropical úmido com estação chuvosa no verão e seca no 
inverno. Apresenta temperatura média anual de $24,5^{\circ} \mathrm{C}$, precipitação média anual de $1.232 \mathrm{~mm}$ e umidade relativa média anual de 64,8\%. O solo da área, onde foi conduzido o experimento é do tipo Latossolo Vermelho distrófico típico, textura argiloso a moderado, alumínico, fortemente ácido.

Foi utilizado no trabalho parcelas com dicotiledôneas, monocotiledôneas e associações de mono e dicotiledôneas para servir de palhada/cobertura vegetal. $O$ delineamento foi o de blocos ao acaso com quatro repetições no esquema fatorial $4 \times 4$. Os tratamentos compreendem os fatores: 1.Dicotiledôneas: a- Guandu, b- Crotalária, c-Nabo forrageiro, d- sem dicotiledônea; 2. Monocotiledôneas : a- Aveia Preta, b- Milheto, cBrachiaria, d-sem monocotiledônea.

A consorciação tem como diferencial a exploração de volume e exigência de nutrientes diferentes das plantas (Monocotiledônea x Dicotiledônea) além contribuírem quantidade de nutrientes para o solo. As culturas que serviram de palhada tinha como características: Nabo forrageiro - cultivar AL1001, semente fiscalizada, pureza 99,8\%,germinação 87\%,peso médio de 1000 sementes 9,4 g, sendo semeado $15 \mathrm{Kg} / \mathrm{ha}$. Crotalaria:Crotalária juncea cultivar IAC-KR-1/categoria S2, semente não tratada, pureza 95\%, germinação 70\%, semeada $25 \mathrm{Kg} / \mathrm{ha}$. Guandu: feijão guandu cultivar fava-larga, semente não tratada, pureza 99\%, germinação 83\%, semeado $50 \mathrm{Kg} / \mathrm{ha}$. Milheto: cultivar BN2/categoria S2, pureza 95\%, germinação 75\%, semeado $20 \mathrm{Kg} / \mathrm{ha}$. Aveia: aveia preta cultivar comum/categoria S2, pureza 95\%, germinação 75\%,70Kg/há Braquiaria: Braquiaria ruziziensis semeados $20 \mathrm{Kg} / \mathrm{ha}$.

Os respectivos tratamento foram implantados a partir de 05 de abril de 2007 com espaçamento de 0,3m entre linha e, quando havia consorcio, as duas culturas envolvidas foram semeadas na mesma linha.

Em 05 de abril de 2007 a área foi sulcada com 0,3m de espaçamento, estaqueada nas delimitações das parcelas, adubado com 8-28-18 de N, P e K respectivamente. A semeadura das culturas que serviram de palhada foi realizada em sempre nos meses de abril dos anos de 2007, 2008 e 2009 e aos 15 dias após a emergência algumas já apresentavam boa cobertura do solo. Após o florescimento das culturas foi realizado o manejo com o 
implemento roçadeira, sendo os restos vegetais deixados sobre a superfície do solo para formação de palhada. Nos meses de setembro dos anos de de condução foram realizadas as avaliações de física do solo.

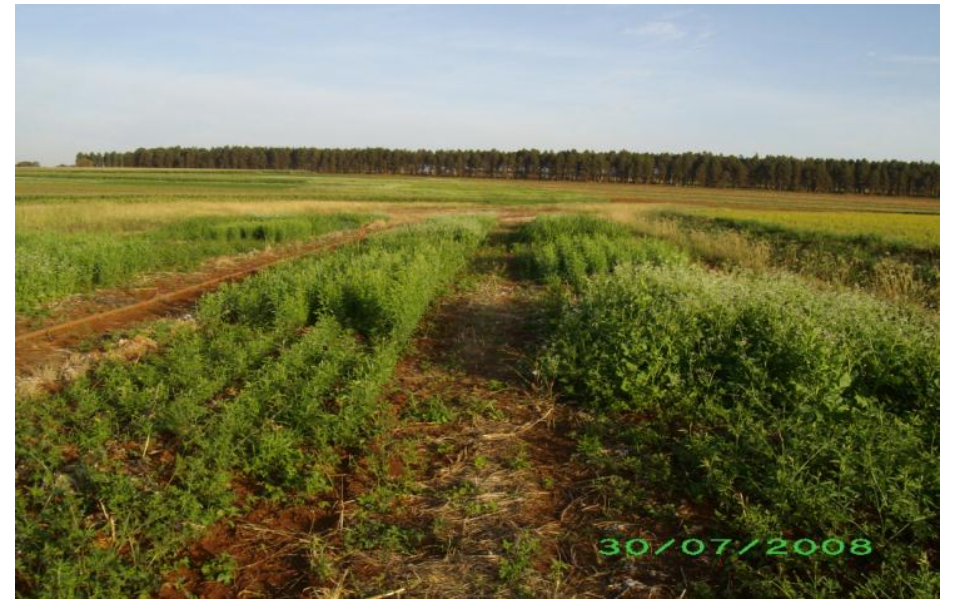

Figura 1- Vista geral do experimento no campo no ano de 2008.

\subsection{Análise física de solo:}

Após a semeadura e manejo das culturas de inverno, na fase de florescimento das culturas foram realizadas para os anos de 2008 e 2009 após o manejo das culturas (roçada) no mês de setembro de cada ano. Foram realizadas análises de resistëcia a penetração do solo nas profundidades de $0-15 ; 15-30 ; 30-45$ e $45-60 \mathrm{~cm}$, utilizando um penetrógrafo tipo Penetrographer $\mathrm{PAT}^{\mathrm{sc}-60}$, cuja metodologia está descrita em Tormena e Roloff, (1996). No mesmo momento foram retiradas amostras de solo com auxilio de trado Tipo Sonda, sendo então acondicionadas em sacos plásticos.

Estas amostras foram encaminhadas para o Departamento de Solos da FE/UNESP/llha Solteira, onde realizou-se a pesagem de cada amostra obtendo assim o peso úmido. $\mathrm{Na}$ sequência estas foram levadas para uma estufa de circulação forçada de ar a uma temperatura de $105^{\circ} \mathrm{C}$. Após 24 horas realizaram-se as leituras de peso seco e por diferença dos pesos (peso úmido - peso seco) foi obtida a umidade gravimétrica.

Os dados obtidos no presente trabalho foram submetidos à análise de variância através do teste $\mathrm{F}$ e teste de comparação de médias (Tukey) para variáveis discretas e 
correlação ao nível de significância de 1 e 5\%, obtendo-se assim diferenças que venham a exprimir os fenômenos ocorridos. Da mesma maneira, procedeu-se a confecção de tabelas que refletiram os fenômenos observados.

\section{RESULTADOS E DISCUSSÃO:}

Na tabela 01 encontram-se os resultados da umidade gravimétrica do solo realizada em 2007, após o manejo das culturas de inverno, para o perfil do solo em função dos tratamentos em estudo. Pela análise da referida tabela verifica-se que somente na profundidade 0-15m ocorreu alteração na umidade em função da utilização das plantas de cobertura, no qual verificou-se a ocorrência da interação entre mono e dicotiledôneas.

Tabela 01 . Valores de p>F e teste de comparação de médias para umidade gravimétrica do solo $\left(\mathrm{kg} \mathrm{kg}^{-1}\right)$, na entre linha de plantio, ao longo do perfil, em função de plantas de cobertura. Selvíria-MS, 2007.

\begin{tabular}{|c|c|c|c|c|}
\hline \multirow{2}{*}{ Teste F } & \multicolumn{4}{|c|}{ profundidades } \\
\hline & $0-15 \mathrm{~cm}$ & $15-30 \mathrm{~cm}$ & $30-45 \mathrm{~cm}$ & $45-60 \mathrm{~cm}$ \\
\hline & \multicolumn{4}{|c|}{$p>F$} \\
\hline Monocot. (m) & 0,3763 & 0,3359 & 0,5876 & 0,5626 \\
\hline Dicot. (d) & 0,6152 & 0,2138 & 0,0518 & 0,6103 \\
\hline \multirow[t]{2}{*}{$m^{*} \mathbf{d}$} & $0,0050^{\pi \pi}$ & 0,8554 & 0,1876 & 0,3646 \\
\hline & \multicolumn{4}{|c|}{$\left(\mathrm{kg} \mathrm{kg}^{-1}\right)$} \\
\hline Sem & 0,156 & 0,166 & 0,187 & 0,204 \\
\hline Aveia preta & 0,159 & 0,167 & 0,188 & 0,204 \\
\hline Brachiaria & 0,157 & 0,170 & 0,187 & 0,188 \\
\hline Milheto & 0,159 & 0,168 & 0,190 & 0,187 \\
\hline Sem & 0,157 & 0,166 & 0,190 & 0,187 \\
\hline Nabo forrageiro & 0,159 & 0,167 & 0,186 & 0,202 \\
\hline Feijão Guandu & 0,157 & 0,170 & 0,186 & 0,190 \\
\hline Crotalária & 0,158 & 0,167 & 0,190 & 0,204 \\
\hline C.V. \% & 3,17 & 3,09 & 2,84 & 5,74 \\
\hline D.M.S. & 0,0055 & 0,0057 & 0,0059 & 0,0429 \\
\hline
\end{tabular}


**, * Significativo aos níveis de $1 \%$ e 5\% respectivamente pelo Teste F da análise de variância. Médias seguidas pela mesma letra na vertical não diferem entre si pelo teste de Tukey a $5 \%$ de probabilidade.

Na tabela 02 constam os valores da umidade gravimétrica do solo na profundidade 0 $15 \mathrm{~cm}$ em função da interação entre os tratamentos em estudo. Pode-se observar que a variação nos teores de umidade gravimétrica ocorreu nos tratamentos nabo forrageiro associado às monocotiledôneas Aveia preta, Milheto e Brachiaria respectivamente em ordem crescente em relação ao tratamento nabo forrageiro somente, que obteve valores inferiores. Ocorreu ainda variação de valores nos tratamentos brachiaria associada à nabo forrageiro e crotalária, que diferiram significativamente dos demais tratamentos, sendo que a interação entre Nabo forrageiro com brachiaria apresentou o maior valor de umidade gravimétrica do solo.

Tabela 02 . Interação entre as diferentes plantas de cobertura para umidade gravimétrica do solo $\left(\mathrm{kg} \mathrm{kg}^{-1}\right)$, de 0-15 cm de profundidade, na entre linha de plantio. Selvíria-MS, 2007.

\begin{tabular}{ccccc}
\hline & \multicolumn{4}{c}{ Monocotiledôneas } \\
Dicotiledôneas & Sem & Aveia preta & Brachiaria & Milheto \\
\hline Sem & 0,159 & 0,161 & $0,152 \mathrm{~b}$ & 0,157 \\
Nabo forrageiro & $0,151 \mathrm{~B}$ & $0,158 \mathrm{AB}$ & $0,167 \mathrm{a} \mathrm{A}$ & $0,162 \mathrm{~A}$ \\
Feijão Guandu & 0,160 & 0,162 & $0,153 \mathrm{~b}$ & 0,153 \\
Crotalária & 0,156 & 0,157 & $0,156 \mathrm{ab}$ & 0,163 \\
D.M.S. & & & &
\end{tabular}

Médias seguidas da mesma letra minúscula na vertical e maiúscula na horizontal não diferem entre si pelo teste de Tukey, ao nível de $5 \%$ de probabilidade.

Os valores de resistência à penetração para o ano agrícola de 2007 realizados após o manejo das cultura de inverno estão apresentados na tabela 03. Pela análise dos resultados obtidos verifica-se que nas profundidades estudadas $(0-15,15-30,30-45$ e 45-60 cm ) não foi possível verificar diferença significativa em função dos tratamentos utilizados.

De posse desses resultados pode-se classificar a resistência a penetração deste solo (ARSHAD et al. 1996) com sendo alta. 


\section{FÓRUM AMBIENTAL DA ALTA PAULISTA}

Volume VI - Ano 2010

Instituição Organizadora: ANAP - Associação Amigos da Natureza da Alta Paulista

ANAP

Relatos de Martins (2002), ao estudar a resistência mecânica a penetração de um Latossolo Vermelho distrófico de acordo com o grau de umidade, nas condições de Selvíria (MS), observou que, após o encharcamento completo do solo, com 4,2 dias de secamento contínuo, o valor da umidade gravimétrica ficou ao redor de $0,2107 \mathrm{~kg} . \mathrm{Kg}^{-1}$, muito próximo da capacidade de campo e equivalendo a uma resistência de 2,0 MPa, sendo tais valores próximos dos encontrados neste trabalho. Já Kamimura (2004) estudando resistência à penetração em 3 sistemas de cultivo (plantio direto, cultivo mínimo e concencional) no mesmo tipo de solo obteve valores inferiores a 2,0 MPa quando em solo manejado com lâminas de irrigação, o que demonstra que a variação à resistência em Latossolo Vermelho distrófico está diretamente relacionada com a umidade do solo.

Tabela 3 . Valores de $\mathrm{p}>\mathrm{F}$ e teste de comparação de médias para resistência à penetração (MPa), na entre linha do algodoeiro, ao longo do perfil, em função de plantas de cobertura, Selvíria-MS. ano agrícola 2007.

\begin{tabular}{|c|c|c|c|c|}
\hline \multirow{2}{*}{ Teste F } & \multicolumn{4}{|c|}{ profundidades } \\
\hline & $0-15 \mathrm{~cm}$ & $15-30 \mathrm{~cm}$ & $30-45 \mathrm{~cm}$ & $45-60 \mathrm{~cm}$ \\
\hline & \multicolumn{4}{|c|}{$p>F$} \\
\hline Monocot. (m) & 0,1247 & 0,2012 & 0,6921 & 0,1156 \\
\hline Dicot. (d) & 0,8635 & 0,1403 & 0,2988 & 0,5307 \\
\hline \multirow[t]{2}{*}{$m^{*} d$} & 0,1077 & 0,0579 & 0,0514 & 0,5466 \\
\hline & \multicolumn{4}{|c|}{ (MPa) } \\
\hline Sem & 2,566 & 2,933 & 3,325 & 3,466 \\
\hline Aveia preta & 2,400 & 2,583 & 3,400 & 3,458 \\
\hline Brachiaria & 2,941 & 2,666 & 3,366 & 3,866 \\
\hline Milheto & 2,258 & 2,591 & 3,208 & 3,525 \\
\hline Sem & 2,600 & 2,533 & 3,266 & 3,516 \\
\hline Nabo forrageiro & 2,391 & 2,891 & 3,191 & 3,625 \\
\hline Feijão Guandu & 2,608 & 2,550 & 3,333 & 3,716 \\
\hline Crotalária & 2,566 & 2,800 & 3,508 & 3,458 \\
\hline C.V. \% & 27,91 & 16,48 & 12,45 & 12,82 \\
\hline D.M.S. & 0,799 & 0,492 & 0,468 & 0,519 \\
\hline
\end{tabular}

** , * Significativo aos níveis de 1\% e 5\% respectivamente pelo Teste $\mathrm{F}$ da análise de variância. Médias seguidas pela mesma letra na vertical não diferem entre si pelo teste de Tukey a $5 \%$ de probabilidade. 


\section{FÓRUM AMBIENTAL DA ALTA PAULISTA}

Volume VI - Ano 2010

Instituição Organizadora: ANAP - Associação Amigos da Natureza da Alta Paulista

ANAP

Os valores referentes à umidade gravimétrica do solo para o ano agrícola de 2008 estão apresentados na tabela 04. De posse dos resultados pode-se verificar que após o manejo das culturas coberturas vegetais, não foram encontradas diferenças nas médias de umidade para as profundidades do solo avaliadas no trabalho.

Tabela 04. Valores de $\mathrm{p}>\mathrm{F}$ e teste de comparação de médias para umidade gravimétrica do solo $\left(\mathrm{kg} \mathrm{kg}^{-1}\right)$, na linha de cultivo, ao longo do perfil, em função de plantas de cobertura. Selvíria-MS, ano agrícola 2008.

\begin{tabular}{ccccc}
\hline \multirow{2}{*}{ Teste $\mathbf{F}$} & \multicolumn{4}{c}{ profundidades } \\
\cline { 2 - 5 } & $\mathbf{0 - 1 5} \mathbf{c m}$ & $\mathbf{1 5 - 3 0} \mathbf{~ c m}$ & $\mathbf{3 0 - 4 5} \mathbf{~ c m}$ & $\mathbf{4 5 - 6 0} \mathbf{~ c m}$ \\
\cline { 2 - 5 } Monocot. (m) & 0,2473 & 0,4828 & 0,7747 & 0,7954 \\
Dicot. (d) & 0,5361 & 0,6294 & 0,0364 & 0,1292 \\
$\mathbf{m}^{*} \mathbf{d}$ & 0,0598 & 0,1566 & 0,0643 & 0,0549 \\
\hline & & \multicolumn{3}{c}{$\mathbf{( \mathbf { k g ~ k g } ^ { - 1 } )}$} \\
Sem & 0,187 & 0,198 & 0,217 & 0,233 \\
Aveia preta & 0,190 & 0,199 & 0,217 & 0,232 \\
Brachiaria & 0,186 & 0,200 & 0,216 & 0,231 \\
Milheto & 0,188 & 0,197 & 0,218 & 0,231 \\
\hline Sem & 0,187 & 0,198 & 0,219 & 0,230 \\
Nabo forrageiro & 0,189 & 0,198 & 0,215 & 0,229 \\
Feijão Guandu & 0,188 & 0,198 & 0,215 & 0,234 \\
Crotalária & 0,187 & 0,200 & 0,220 & 0,234 \\
\hline C.V. \% & 2,37 & 2,03 & 2,23 & 2,90 \\
D.M.S. & 0,0049 & 0,0044 & 0,0053 & 0,0074
\end{tabular}

**, * Significativo aos níveis de 1\% e 5\% respectivamente pelo Teste $\mathrm{F}$ da análise de variância. Médias seguidas pela mesma letra na vertical não diferem entre si pelo teste de Tukey a $5 \%$ de probabilidade.

Os resultados da análise de resistência à penetração realizados no ano agrícola de 2008 em função dos tratamentos em estudo estão apresentados na tabela 05. De posse dos resultados, observa-se diferenças somente dentre os tratamentos conduzidos por monocotiledôneas na profundidade $0-15 \mathrm{~cm}$, demonstrando que nos tratamentos 
testemunha, brachiaria e milheto em ordem crescente proporcionaram uma maior resistência se comparado ao tratamento aveia preta. Salienta-se ainda uma vez mais que os valores encontrados no estudo são classificados como alta a muito alta (ARSHAD et al. 1996). Tais valores foram obtidos muito provavelmente, pela pouca umidade do solo neste período do ano. Essa baixa umidade é característica da região, que apresenta um inverno quente e seco, sendo essas condições essenciais para que se tenha pouca umidade, resultando em altos valores de resistência a penetração. $O$ fato deste aumento na resistência encontrar-se alto na camada superior do solo pode estar atrelado ao maior volume radicular, principalmente das gramíneas (tipo fasciculada), o que pode intensificar ainda mais à baixa umidade em períodos de estiagem.

Tabela 05. Valores de p>F e teste de comparação de médias para resistência à penetração (MPa), na linha do algodoeiro, ao longo do perfil, em função de plantas de cobertura. Selvíria-MS, ano agrícola 2008.

\begin{tabular}{|c|c|c|c|c|}
\hline \multirow{2}{*}{ Teste F } & \multicolumn{4}{|c|}{ profundidades } \\
\hline & $0-15 \mathrm{~cm}$ & $15-30 \mathrm{~cm}$ & $30-45 \mathrm{~cm}$ & $45-60 \mathrm{~cm}$ \\
\hline & \multicolumn{4}{|c|}{$p>F$} \\
\hline Monocot.(m) & 0,0286 & 0,0751 & 0,0817 & 0,4759 \\
\hline Dicot. (d) & 0,1425 & 0,0922 & 0,1661 & 0,0116 \\
\hline \multirow{2}{*}{$\mathbf{m}^{\star} \mathbf{d}$} & 0,2575 & 0,0600 & 0,0813 & 0,8061 \\
\hline & \multicolumn{4}{|c|}{ (MPa) } \\
\hline Sem & $1,941 a b$ & 2,283 & 3,141 & 3,108 \\
\hline Aveia preta & $1,741 b$ & 2,550 & 2,575 & 3,391 \\
\hline Brachiaria & $2,083 a b$ & 2,600 & 2,866 & 3,300 \\
\hline Milheto & $2,333 a$ & 2,650 & 2,816 & 3,308 \\
\hline Sem & 1,891 & 2,316 & 3,100 & $3,583 \mathrm{a}$ \\
\hline Nabo forrageiro & 2,041 & 2,575 & 2,616 & $2,925 \mathrm{~b}$ \\
\hline Feijão Guandu & 2,283 & 2,691 & 2,808 & $3,275 a b$ \\
\hline Crotalária & 1,883 & 2,500 & 2,875 & $3,325 a b$ \\
\hline C.V. \% & 22,89 & 14,10 & 18,00 & 13,72 \\
\hline D.M.S. & 0,511 & 0,398 & 0,579 & 0,492 \\
\hline
\end{tabular}

** , Significativo aos níveis de 1\% e 5\% respectivamente pelo Teste $\mathrm{F}$ da análise de variância. Médias seguidas pela mesma letra na vertical não diferem entre si pelo teste de Tukey a $5 \%$ de probabilidade. 


\section{FÓRUM AMBIENTAL DA ALTA PAULISTA}

Volume VI - Ano 2010

Para o ano agrícola de $2008 / 9$ os resultados das médias para umidade gravimétrica do solo na linha de plantio estão apresentados na tabela 07 . Nesta profundidade houve efeito da interação entre plantas monocotiledôneas e dicotiledôneas umidade gravimétrica na linha do algodoeiro onde a tabela revela os desdobramentos dos resultados. Verifica-se que para o desdobramento de monocotiledôneas dentro de dicotiledôneas os tratamentos sem as leguminosas a aveia preta apresentou valores superiores de umidade se comparado à brachiaria. Porém quando consorciada com o nabo forrageiro, a brachiaria apresenta a situação inversa, com maior valor de umidade, diferindo do tratamento nabo somente. Para os consórcios com guandu e crotalária a brachiaria continua apresentando valores superiores à guandu sozinho e à associação de aveia com crotalária respectivamente.

Tabela 06. Valores de $\mathrm{p}>\mathrm{F}$ e teste de comparação de médias para umidade gravimétrica do solo $\left(\mathrm{kg} \mathrm{kg}^{-1}\right)$, na linha de plantio, ao longo do perfil, em função de plantas de cobertura, Selvíria-MS, ano agrícola 2009.

\begin{tabular}{|c|c|c|c|c|}
\hline \multirow{2}{*}{ Teste F } & \multicolumn{4}{|c|}{ profundidades } \\
\hline & $0-15 \mathrm{~cm}$ & $15-30 \mathrm{~cm}$ & $30-45 \mathrm{~cm}$ & $45-60 \mathrm{~cm}$ \\
\hline & \multicolumn{4}{|c|}{$p>F$} \\
\hline Monocot.(m) & 0,0823 & 0,0153 & 0,2347 & 0,6040 \\
\hline Dicot. (d) & $0,0188^{*}$ & 0,8131 & 0,0840 & 0,8597 \\
\hline \multirow[t]{2}{*}{$m^{\star} d$} & $0,0010^{* \pi}$ & 0,0977 & 0,0523 & 0,6535 \\
\hline & \multicolumn{4}{|c|}{$\left(\mathrm{kg} \mathrm{kg}^{-1}\right)$} \\
\hline Sem & 0,161 & $0,166 \mathrm{~b}$ & 0,207 & 0,216 \\
\hline Aveia preta & 0,160 & $0,169 a b$ & 0,205 & 0,220 \\
\hline Brachiaria & 0,164 & $0,166 \mathrm{~b}$ & 0,200 & 0,218 \\
\hline Milheto & 0,162 & $0,174 a$ & 0,1972 & 0,218 \\
\hline Sem & $0,160 \mathrm{ab}$ & 0,169 & 0,194 & 0,220 \\
\hline Nabo forrageiro & $0,161 \mathrm{ab}$ & 0,167 & 0,206 & 0,218 \\
\hline Feijão Guandu & $0,165 \mathrm{a}$ & 0,168 & 0,207 & 0,217 \\
\hline Crotalária & $0,159 \mathrm{~b}$ & 0,170 & 0,202 & 0,217 \\
\hline C.V. \% & 2,47 & 3,74 & 6,50 & 3,75 \\
\hline D.M.S. & 0,0044 & 0,0070 & 0,0146 & 0,0091 \\
\hline
\end{tabular}


**, * Significativo aos níveis de 1\% e 5\% respectivamente pelo Teste $\mathrm{F}$ da análise de variância. Médias seguidas pela mesma letra na vertical não diferem entre si pelo teste de Tukey a $5 \%$ de probabilidade,

Tabela 07 . Interação entre as diferentes plantas de cobertura para umidade gravimétrica do solo $\left(\mathrm{kg} \mathrm{kg}^{-1}\right) \mathrm{na}$ linha do algodoeiro, de 0-15 cm de profundidade. Selvíria-MS, 2009.

\begin{tabular}{ccccc}
\hline \multirow{2}{*}{ Dicotiledôneas } & Sem & Aveia preta & Brachiaria & Milheto \\
\hline Sem & $0,158 \mathrm{~b} \mathrm{AB}$ & $0,165 \mathrm{a} \mathrm{A}$ & $0,156 \mathrm{~b} \mathrm{~B}$ & $0,164 \mathrm{AB}$ \\
Nabo forrageiro & $0,157 \mathrm{~b} \mathrm{~B}$ & $0,163 \mathrm{a} \mathrm{AB}$ & $0,166 \mathrm{ab} \mathrm{A}$ & $0,158 \mathrm{AB}$ \\
Feijão Guandu & $0,161 \mathrm{ab} \mathrm{B}$ & $0,163 \mathrm{a} \mathrm{AB}$ & $0,171 \mathrm{a} \mathrm{A}$ & $0,164 \mathrm{AB}$ \\
Crotalária & $0,167 \mathrm{a} \mathrm{A}$ & $0,149 \mathrm{~b} \mathrm{~B}$ & $0,163 \mathrm{ab} \mathrm{A}$ & $0,158 \mathrm{~A}$
\end{tabular}

D.M.S.

Médias seguidas da mesma letra minúscula, na vertical, não diferem entre si pelo teste de Tukey, ao nível de $5 \%$ de probabilidade. Médias seguidas da mesma letra maiúscula, na horizontal, não diferem entre si pelo teste de Tukey, ao nível de 5\% de probabilidade.

Para a comparação de médias de resistência a penetração conduzida no ano agrícola de 2009 o teste estatístico evidenciou diferenças nas profundidades de $0-15 \mathrm{~cm}$ e na profundidade de $30-45 \mathrm{~cm}$ da superfície do solo. Na primeira situação, após 3 anos de culturas de cobertura sendo conduzidas na mesma área, demonstrou que nos primeiros 15 cm de solo as diferenças para resistência á penetração ocorrem nos tratamentos conduzidos por monocotiledôneas. Fato este explicado novamente devido a concentração do sistema radicular das monocotiledôneas encontrar-se na camada superior do solo e ser do tipo fasciculada, o que confere sua área de expansão. $O$ tratamento testemunha apresentou os maiores valores de resistência a penetração.

$\mathrm{Na}$ camada de 30 - $45 \mathrm{~cm}$ os tratamentos conduzidos por plantas dicotiledôneas apresentaram diferenças. $O$ tratamento testemunha após 3 anos de cultivo apresentou os maiores valores para resistência a penetração. Os tratamentos Nabo forrageiro, Guandu e crotalária apresentaram valores inferiores. Este fato pode ser explicado também ao fato da ação do volume de raízes, pois nesta profundidade do solo as dicotiledôneas atuam devido o sistema radicular se apresentar de forma pivotante. 
Tabela 08. Valores de $\mathrm{p}>\mathrm{F}$ e teste de comparação de médias para resistência à penetração ( $\mathrm{MPa})$, na linha de plantio, ao longo do perfil, em função de plantas de cobertura. Selvíria-MS, ano agrícola 2009.

\begin{tabular}{|c|c|c|c|c|}
\hline \multirow{2}{*}{ Teste F } & \multicolumn{4}{|c|}{ Profundidades } \\
\hline & $0-15 \mathrm{~cm}$ & $15-30 \mathrm{~cm}$ & $30-45 \mathrm{~cm}$ & $45-60 \mathrm{~cm}$ \\
\hline & \multicolumn{4}{|c|}{$p>F$} \\
\hline Monocot. (m) & 0,0083 & 0,5759 & 0,4283 & 0,1617 \\
\hline Dicot. (d) & 0,1261 & 0,7533 & 0,0486 & 0,9614 \\
\hline \multirow[t]{2}{*}{$M^{\star} d$} & 0,0235 & 0,8498 & 0,2218 & 0,2876 \\
\hline & \multicolumn{4}{|c|}{ (MPa) } \\
\hline Sem & $3,141 \mathrm{a}$ & 2,816 & 2,483 & 3,722 \\
\hline Aveia preta & $2,200 \mathrm{~b}$ & 2,516 & 2,925 & 2,983 \\
\hline Brachiaria & $2,341 b$ & 2,500 & 2,633 & 3,341 \\
\hline Milheto & $2,516 a b$ & 2,450 & 2,625 & 3,233 \\
\hline Sem & 2,591 & 2,608 & $3,100 \mathrm{a}$ & 3,316 \\
\hline Nabo forrageiro & 2,258 & 2,616 & $2,650 a b$ & 3,325 \\
\hline Feijão Guandu & 2,908 & 2,383 & $2,608 \mathrm{ab}$ & 3,233 \\
\hline Crotalária & 2,441 & 2,675 & $2,308 b$ & 3,405 \\
\hline C.V. \% & 26,01 & 27,34 & 24,70 & 23,66 \\
\hline D.M.S. & 0,731 & 0,789 & 0,738 & 0,879 \\
\hline
\end{tabular}

**, * Significativo aos níveis de 1\% e 5\% respectivamente pelo Teste $\mathrm{F}$ da análise de variância. Médias seguidas pela mesma letra na vertical não diferem entre si pelo teste de Tukey a 5\% de probabilidade.

A tabela 10 demonstra a interação entre as diferentes plantas de cobertura para a resistência a penetração de $0-15 \mathrm{~cm}$ de profundidade. $O$ desdobramento das interações demonstrou que o tratamento milheto interagiu com o tratamento testemunha (sem plantas de cobertura). Este fato pode estar atribuído à interferência de espécies de ervas daninhas existentes no tratamento testemunha, pois não foi realizado o controle do mato nestas parcelas. O não controle do mato foi uma ação proposital pois representava as condições naturais de uma área em pousio. Algumas espécies de daninhas podem possuir o sistema radicular de forma a interferir na densidade do solo, principalmente na camada superficial de $0-15 \mathrm{~cm}$. $O$ desdobramento demonstra ainda diferenças entre 0 tratamento crotalária 
somente e consórcio brachiaria + crotalária, no qual apresentou valores inferiores de resistência a penetração. Este fato atribui-se possivelmente pelo consórcio apresentar maior volume radicular, na profunidade de $0-15 \mathrm{~cm}$ ocasionado pelo sistema radicular da brachiaria presente nesta faixa de profunidade. Mesmo o desdobramento das plantas dicotiledonares dentro da monocotiledônea milheto ocorre o mesmo fenômeno e atribui-se à mesma causa, onde o tratamento milheto somente apresenta a concentração radicular na superfície $0-15$, diferindo do consórcio milheto + guandu.

Tabela 10. Interação entre as diferentes plantas de cobertura para resistência à penetração (MPa) de $0-15 \mathrm{~cm}$ de profundidade, na linha do algodoeiro. Selvíria-MS, 2009.

\begin{tabular}{ccccc}
\hline & \multicolumn{4}{c}{ Monocotiledôneas } \\
Dicotiledôneas & Sem & Aveia preta & Brachiaria & Milheto \\
\hline Sem & $3,900000 \mathrm{~A}$ & $1,833333 \mathrm{~B}$ & $2,90000 \mathrm{AB}$ & $1,733333 \mathrm{~b} \mathrm{~B}$ \\
Nabo forrageiro & 2,566667 & 1,966667 & 2,233333 & $2,26666 \mathrm{ab}$ \\
Feijão Guandu & 3,100000 & 2,266667 & 2,800000 & $3,466667 \mathrm{a}$ \\
Crotalária & $3,000000 \mathrm{~A}$ & $2,73333 \mathrm{AB}$ & $1,433333 \mathrm{~B}$ & $2,600000 \mathrm{ab} \mathrm{AB}$
\end{tabular}

D.M.S.

1,47314518319525

Médias seguidas da mesma letra minúscula na vertical e maiúscula na horizontal, não diferem entre si pelo teste de Tukey, ao nível de $5 \%$ de probabilidade.

\section{CONCLUSÃO}

Os atributos físicos do solo de umidade gravimétrica e resistência à penetração são modificados após 3 anos de cultivo de plantas de cobertura. A camada superficial do solo correspondente à profunidade de zero à quinze centímetros é interferida pelo cultivos de plantas monocotiledôneas e as camadas mais profundas, de trinta à $45 \mathrm{~cm}$ são alteradas por plantas dicotiledôneas quanto à resistência à penetração.

\section{REFERÊNCIAS}




\section{FÓRUM AMBIENTAL DA ALTA PAULISTA}

Volume VI - Ano 2010

ALCÂNTARA, P. B.; BUfARAH, G. Plantas forrageiras: gramíneas \& leguminosas. 3. ed. São Paulo: Nobel, 1986. $150 p$

ARSHAD, M.A.; LOWERY, B.; GROSSMAN, B. Physical tests for monitoring soil quality. In: DORAN, J.W.; JONES, A.J. (Ed.). Methods for assessing soil quality. Madison : Soil Science Society of America, 1996. p.123-141. (SSSA Special Publication, 49).

COSTA, F.S; ALBUQUERQUE, J. A.; BAYER, C. ; FONTOURA, S. M. V.; WOBETO, C. Propriedades físicas de um latossolo Bruno afetadas pelos sistemas plantio direto e preparo convencional. Revista Brasileira de Ciência do Solo, Campinas, v.27, p.527-535,2003.

KAMIMURA, K.M. Manejo do solo e da água nas propriedades físicas, químicas e térmicas do solo e produtividade do arroz de terras altas. 2005. 127p. Trabalho de graduação FE/UNESP, Ilha Solteira.

Köppen, W. 1948. Climatologia: con un estudio de los climas de la tierra. Fondo de Cultura Econômica. México. 479p.

MARTINS, C.B. Análise da resistência mecânica à penetração de um Latossolo Vermelho distrófico em função do grau de umidade. 2002. 46 f. Monografia (Trabalho de Graduação) Faculdade de Engenharia de Ilha Solteira, Universidade Estadual Paulista, Ilha Solteira, 2002.

OTTONI FILHO, T.B. "Uma classificação fisico-hidrica dos solos". R. Brasileira de Ciência do Solo, v.27, pp. 211-222, 2003.

TORMENA, C.A.; ROLOFF, G. Dinâmica da resistência à penetração de um solo sob plantio direto. Revista Brasileira de Ciência do Solo, v.20, p.333-339, 1996. 